\title{
Research on the Development of CPA Audit from the Perspective of Artificial Intelligence
}

\author{
Authors Name: Guangxiu Zhou ${ }^{1 *}$ \\ ${ }^{1}$ Accounting School, Harbin Finance University, Harbin, China
}

\begin{abstract}
In the context of the continuous development of Internet technology, big data, Internet of things, cloud computing and other technologies have developed rapidly, and artificial intelligence technology has emerged as the times require. The development of new technologies has promoted social change. As soon as artificial intelligence technology is put forward, it has been widely concerned by the society. Artificial intelligence is like a double-edged sword. As an emerging technology, it is constantly influencing all walks of life, and its application in the field of audit has become the general trend. Under the Background of the rise of artificial intelligence, this paper puts forward the advantages of the combination of artificial intelligence and audit, and analyzes the challenges faced by the development of CPA audit industry, seize the opportunity of the times, actively apply artificial intelligence technology, give practical suggestions for the long-term development of the audit industry, in order to improve the audit efficiency and ensure the audit effect.
\end{abstract}

\section{INTRODUCTION}

Artificial intelligence is a theory, method, technology and application system that uses digital computer or machine controlled by digital computer to simulate, extend and expand human intelligence, perceive environment, acquire knowledge and use knowledge to obtain the best results. It is designed by human beings and serves for human beings. Its essence is computation and its basis is data. It can perceive reaction, interact with people and complement each other. The emergence of Xiao qin ren, a financial robot developed by Deloitte, one of the four famous international accounting firms, indicates that artificial intelligence has officially entered the field of financial audit. Price Waterhouse Coopers uses "RPA" robot to realize automatic operation. The application of artificial intelligence technology can effectively solve the problems of repeatability, heavy workload and tedious data analysis of accounting firms. Artificial intelligence robot can imitate the daily work of auditors, so that auditors can put more energy on complex work such as audit procedures[1]. In addition to well-known international accounting firms, many audit work have integrated cloud computing, artificial intelligence, cloud storage and other technologies to build a "cloud audit" platform. But in the process of the implementation of artificial intelligence audit, we should pay attention to the possible security risks and find solutions, so that artificial intelligence can develop healthily in the audit field, and really play a role in improving the audit efficiency and ensuring the audit effect.

\section{ADVANTAGES OF ARTIFICIAL INTELLIGENCE}

Artificial intelligence has a congenital advantage in computing power, which is beyond the reach of human brain. Artificial intelligence has no thoughts, feelings and personal preferences, so there will be no motivation for fraud, and the work efficiency of artificial intelligence will be greatly improved. In the traditional mode of employment, the labor cost of enterprises is very high, in addition to pay the wages to employees, but also need to buy a variety of insurance and other benefits. If we use artificial intelligence technology, even if we work 24 hours a day without rest, we will not require enterprises to pay overtime wages, so the introduction of artificial intelligence will reduce the human cost of enterprises and reduce the financial burden of enterprises. In addition to the advantage of computing power, artificial intelligence also has a huge advantage in accuracy[2]. As long as the machine and system are maintained regularly, artificial intelligence can handle affairs according to preset procedures. It can really play a role in improving work efficiency and ensuring work quality.

*Corresponding author: 2009144@hrbfu.edu.cn 


\section{THE COMBINATION OF ARTIFICIAL INTELLIGENCE AND CPA AUDIT}

\subsection{The inevitable trend of "artificial intelligence + audit"}

The audit work of traditional accounting firms consists of five steps. (Figure 1)

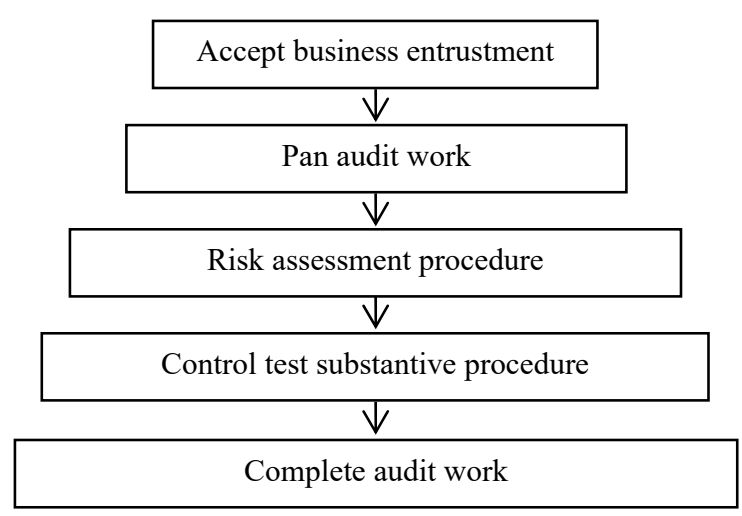

Figure 1. Traditional audit work flow chart.

From accepting business entrustment to issuing audit report, certified public accountants must rely on their own audit experience and professional competence to complete the audit work, and spend a lot of time and energy in the process of doing a lot of basic work. Artificial intelligence technology has many advantages in computing speed and accuracy that human brain cannot reach. It is an inevitable trend to apply these advantages to the audit industry. Artificial intelligence audit is the application of artificial intelligence system and machine in audit work. Through big data, cloud computing and other emerging technologies, audit the financial data and related data of the audited unit, it can assist the CPA to quickly extract valuable information from a large number of data and automatically form the differences in the verification documents. At the same time, CPAs can put more energy into unstructured audit tasks such as audit judgment. With the application of artificial intelligence technology, the audit evidence obtained by certified public accountants is more adequate and appropriate to avoid all kinds of risks caused by manual operation. (Figure 2)

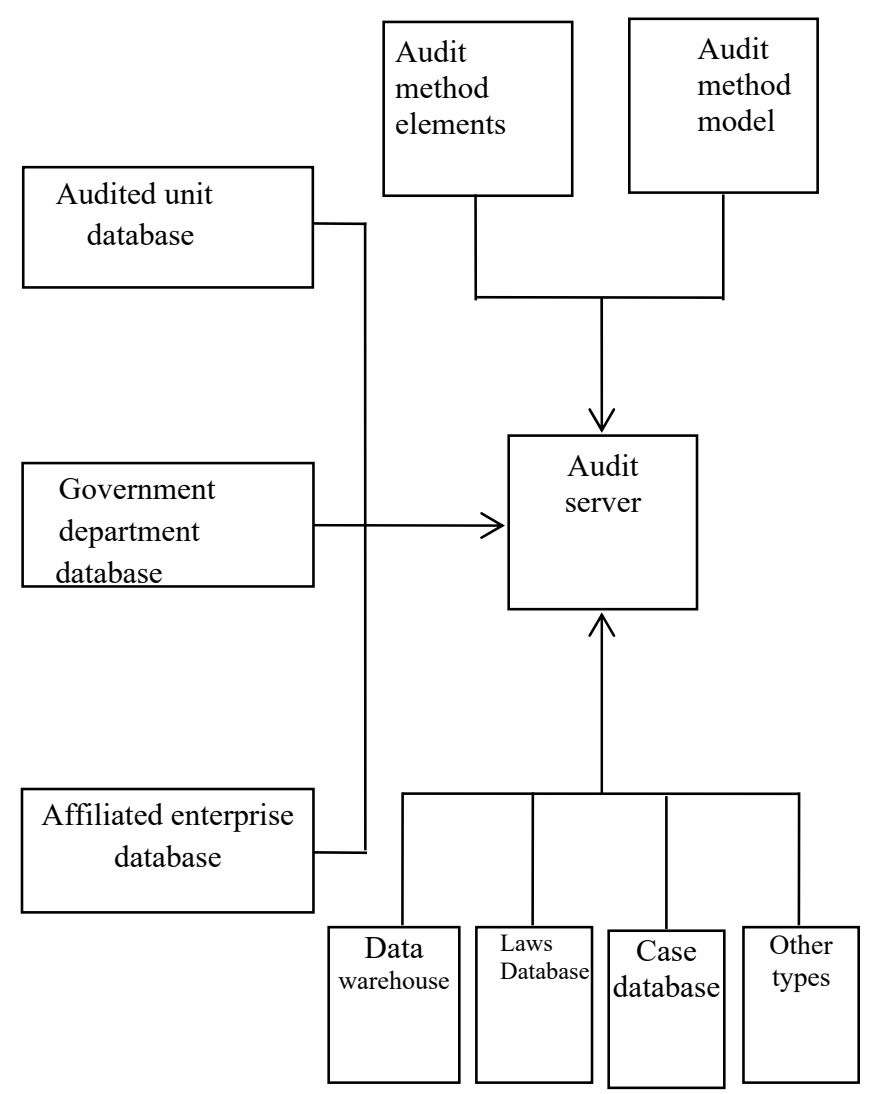

Figure 2. Flow chart of artificial intelligence audit.

\subsection{The influence of artificial intelligence on audit}

3.2.1 Big data is the technical support of artificial intelligence audit. Artificial intelligence audit cannot do without the support of big data. Big data processing system uses swarm intelligence to replace individual intelligence in driving expression and learning cognitive reasoning. We use artificial intelligence technology in many fields to realize the automation of audit work, carry out data analysis and audit evidence collection around the core idea of data center[3]. In the era of artificial intelligence, the collection scope of audit data is no longer limited to structured data and unstructured data. Intelligent robots or software systems can collect a wider range of image data, video data, audio data, structured data and other types of unstructured data. (Figure 3 )

3.2.2 Artificial intelligence changes audit direction. In the era of artificial intelligence, auditing should not be limited to correcting and checking the defects, and examining the authenticity and reliability of financial statements. The development direction of modern audit is risk oriented audit, from post audit to pre audit and in-process audit, strengthen the rationality and feasibility of budget, plan, forecast and decision-making, and control the economic activities in the process of implementing the plan. 


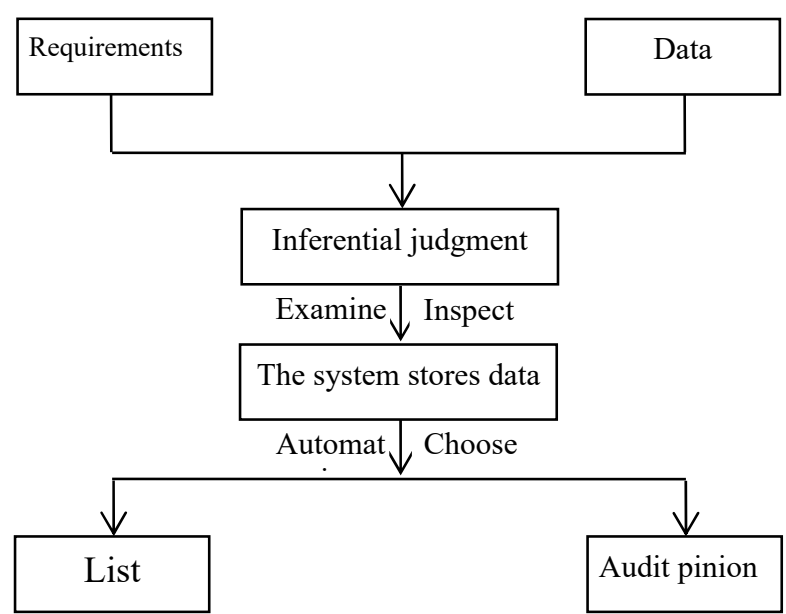

Figure 3. Audit Data Center

Artificial intelligence technology is applied to all aspects of audit. (Table 1) The core of artificial intelligence audit has changed from the prevention of fraud and error detection to the increase of value and the improvement of organizational operation efficiency, providing predictive reports and forward-looking audit suggestions for the development of the audited units, optimizing the management mechanism and organizational structure of the audited units, and doing well in audit early warning, so as to ultimately promote the sound economic operation of the audited units[4].

\subsubsection{Artificial intelligence audit can reduce audit risk.} In the traditional audit work, the CPA is limited by the cost-benefit principle, and it is difficult to conduct a comprehensive audit and detailed audit on the audited unit. Audit sampling is bound to become an important method to carry out the audit work. Under the condition of artificial intelligence, CPA can collect more or even all the data of the audited unit for detailed investigation, so as to reduce the sampling risk brought by the use of sampling method. Using Artificial intelligence technology, certified public accountants can save time cost and labor cost, ensure the sufficiency and appropriateness of audit evidence, make it easier to draw objective and fair audit conclusions, and control the acceptable inspection risk level of certified public accountants.

\section{Challenges and Countermeasures of artificial intelligence audit}

The development and application of new technologies such as artificial intelligence, big data, cloud computing and blockchain are inevitable laws of historical development, which cannot be stopped. New technology is just like a double-edged sword. All walks of life are facing both opportunities and challenges. The audit industry is also facing great opportunities and challenges.
TABLE I. APPLICATION OF ARTIFICIAL INTELLIGENCE IN AUDIT

\begin{tabular}{|c|c|c|}
\hline Technical name & application area & $\begin{array}{c}\text { Application in } \\
\text { auditing }\end{array}$ \\
\hline big data & Full sample test & Full sample audit \\
\hline $\begin{array}{c}\text { cloud } \\
\text { computing }\end{array}$ & $\begin{array}{c}\text { Real time access } \\
\text { to enterprise data }\end{array}$ & Audit data sharing \\
\hline $\begin{array}{c}\text { Blockchain } \\
\text { Technology }\end{array}$ & Network currency & $\begin{array}{c}\text { Simultaneous real } \\
\text { time audit }\end{array}$ \\
\hline E-mail & $\begin{array}{c}\text { Sort email by } \\
\text { type }\end{array}$ & Audit data analysis \\
\hline GPS & $\begin{array}{c}\text { satellite } \\
\text { positioning }\end{array}$ & Prevention of fraud \\
\hline
\end{tabular}

\subsection{Artificial intelligence audit faces security challenge.}

We are good at using emerging technologies such as big data and artificial intelligence to improve audit professional skills. However, we should not exaggerate the magic of new technologies such as data and artificial intelligence, and we should guard against the possible security risks. The security risk of artificial intelligence has always been a core issue for scientists and technicians, therefore, to solve the security risk of artificial intelligence products, we need a combination of various means, not only the constraints of laws and regulations, but also strict application boundary restrictions. CPA cannot rely solely on artificial intelligence in the audit process, but also needs to abide by the occupation ethics of CPAs and maintain the spirit of legitimate questioning, and maintain close communication and communication with the relevant personnel of the audited units. Although artificial intelligence can process huge data quickly and conduct in-depth analysis and integration, it lacks the ability of audit communication[5]. If certified public accountants rely too much on computers and reduce communication time with relevant personnel, they will have an impact on the accuracy of audit judgment, resulting in the loss of objectivity and fairness in audit reports, thus creating audit risks.

\subsection{Universities and accounting firms are facing the challenge of training new audit talents.}

Each emerging technology application will bring auditors' "technical unemployment" and promote the growth of demand for new audit talents. Faced with this severe challenge, universities and accounting firms should build a multi professional ability framework with audit thinking as the core, strengthen the cultivation of reverse thinking of audit talents, learn to suspect properly and pay attention to abnormal changes, and gradually improve the data analysis ability and judgment level of auditors. The audit profession and its employees should only adapt to this change and innovate continuously, and combine the advantages of artificial intelligence with the professional competence of auditors, and strive to improve their competitiveness in practice, so as to 
advance the development of audit industry in accordance with the progress of the times.

\section{5 conclusion}

The development of artificial intelligence not only brings challenges to accounting firms, but also provides more opportunities. Accounting firms should change traditional audit thinking as soon as possible, integrate, promote and develop AI theory and audit theory, and actively strengthen the development and application of cloud services, big data, Internet of things and other information technologies in audit work, we should optimize audit procedures, improve the comprehensive quality and professional ability of auditors, promote the continuous expansion of the survival and development space of accounting firms, and improve the audit quality, audit efficiency and audit service level of accounting firms.

\section{Acknowledgment}

This work is supported by Heilongjiang Philosophy and Social Science Research Planning Project (No.20JYE268).

\section{References}

1. Wu, M. (2018) The impact of blockchain technology on natural resource assets audit. J. Cooperative economy and science and technology., 12: 158-159.

2. Gu, BH. (2020) Application of blockchain technology in government audit. J. Finance and accounting., 3: 51-59.

3. Chen, GF. (2020) Application prospect of blockchain technology in water resources management. J. Water conservancy Hydropower Technology., 6: 11-16.

4. Zhou, GX. (2016) Analysis of the problems that should be paid attention to in the leaving audit of natural resources assets. J. Industry and Technology Forum., 22: 229-230.

5. Jiang, WL. (2019) Prospect of blockchain audit technology. J. Audit monthly., 12: 4-6. 